\title{
Preparation and study of the structural and optical properties of silver nanoparticles prepared from extracts of some plants
}

\author{
Alyaa Hussein Ali ${ }^{1}$, Huda Zeki Abd Al Rahman ${ }^{2}$, Rihab Jumaah Mansoor ${ }^{3}$ \\ Aseel Jamal Ahmed ${ }^{4}$ \\ 1,2 Department of physics, College of science, Diyala university. Iraq. \\ ${ }^{3}$ Department of Biology, College of science, Diyala university. Iraq \\ ${ }^{4}$. Department of Chemistry, College of science, Diyala university. Iraq \\ alyaahussein@uodiyala.edu.iq, hudazeki206@gmail.com , \\ Rehabjumaa@uodiyala.edu.iq, aseeljamal@uodiyala.edu.iq
}

\begin{abstract}
The study included the preparation of silver nanoparticals using Punica granatum extract . as silver nanoparticals were prepared by biological method. which is one of the best ways for its cheapness and the fact that is does not require time and does not leave toxic substance in the study, the active compounds of the extract were detected and some physical properties of AgNps were studied . the optical and structural properties of the prepared nanoparticles were studied by Uv-Visible spectrophoto meter measurement. perform an infrared spectrophotometric test (FTIR) a filed - emitting scanning electron microscope was also performed, ( EDX) , (X-RAY) and the results of ( FESEM ) measurement showed

that silver nanoparticles are of oval shape, and of different sizes ranging from ( $32.55-70.55) \mathrm{nm}$. with a rate of $(45.98) \mathrm{nm}$.

Keywords: Punica granatum plant, silver nitrate, ethanol alcohol.

DOI: $10.7176 /$ APTA/85-03

Publication date: December $30^{\text {th }} 2021$

\section{INTRODUCTION}

This study aims to synthesize nanoparticles in the green way using the leaves of the Punica granatum plant . nanoparticles are great importance at the present time and are used in many fields [1]. the interest in preparing nanoparticles has increased alot especially in the recent period, especially in biosynthesis because these particles have distinct chemical, electronic and optical properties, and they can be changed depending on the size and shape of the particles, which allows them to be used in various applications . the particles prepared by biological methods are characterized by high purity, good electrical conductivity, chemical stability, and high catalytic activity, which depends on the size of the particles, size distribution, the shape of the particles, the degree of crystallization, the composition and proportions of the components [2]. the biological method does not require high pressure, and high temperature, and the quantity produced is high in a short period [ 3 ]. in general there are two types of methods for preparing nanoparticles, which are top-down and bottom- up methods [4]. A bottom - up technique means building nanoparticles from atoms and molecules, and a top - down technique means dismantling the large- sized materials into smaller particles, which ultimately leads to nanoparticles [ 5]. these nanoparticles (NPS) are of great important as they are an inorganic nano materials, which makes them enter the composition of medicines for the treatment of bacterial diseases, as they are one of the factors used for the effective treatment of microbes, and are used in drug delivery, optical industries, coatings industry and many other fields [6].
\end{abstract}

\section{Materials and methods}

In this study the silver nanoparticles were prepared. the alcohol plant extract was prepared by drying the leaves of the plant and grinding it well

weighing about (150) gm of the plant, then Adding to it ( 100$) \mathrm{ml}$ of ethanol alcohol, leaving it at room temperature until the next day then

filtering the mixture and adding ( 600$) \mathrm{ml}$ of a ( 3 molar ) solution of silver nitrate to it . then it was noticed that the color of the solution changed from light color to dark, which indicates the formation of silver nanoparticles it is shown in figure $(1,2)$. then the physical properties of AgNps were studied using ( x-ray ), (F T I R ), (F E S E M), ( E DX ) and Uv - measurements . as these measurements proved the presence of silver nanoparticles and showed that their shapes are spherical . 


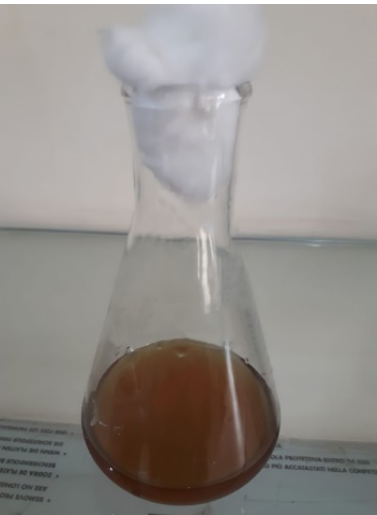

figure (1)

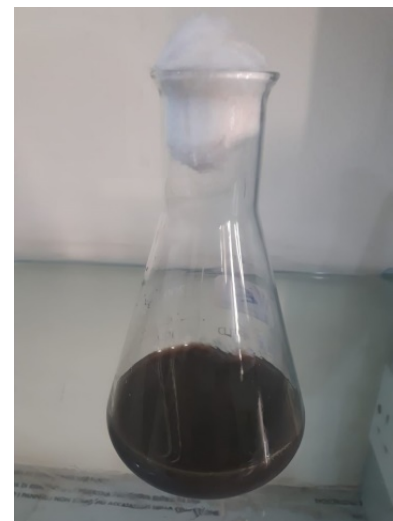

figure (2)

Figure(1) shows solutions represent the plant extract and (2) represent the silver nitrate in the presence of optimized amounts Punica granatum extract solutions after completion of the reaction Previous studies

Researchers have been interested in silver nanoparticles, and dealt with them in many studied because of the effective role of these particles in the field nanotechnology . as the research ( Krishna raj ) prepared silver particles from the aqueous extract of the neem tree by placing (100 ) $\mathrm{ml}$ of (1) $\mathrm{m} \mathrm{M}$ silver nitrate with (12) $\mathrm{ml}$ of the aqueous extract of the plant

[7] .The research ( Shamili ) also prepared nanoparticles from the extract of the Callicarpa maingayi plant, and he measured the Uv - visible of the extract, and the Uv showed the appearance of an absorption peak at (450) $\mathrm{nm}[8]$. the researcher ( Kaushik) also prepared silver nanoparticles from grape fruit as he noticed the change in the color of the solution from light yellow to dark after added (10) $\mathrm{ml}$ of aqueous silver nitrate solution to the plant extract, using transmission electron microscope Tem, he noticed that the silver nanoparticles were spherical in shape with weak

crystal structure with an average size of (20-80) $\mathrm{nm}$ [9].

\section{Results and discussion}

1-Field Emission Scanning Electron Microscopy (FESEM )

The results of scanning field - emitting electron microscopy examination showed that silver nanoparticles are of oval shape, they are scattered on the surface of the pomegranate leaf extract as shown in figure (3) as this examination shows the membrane surfaces of the alcoholic extract of the plant and AgNps after being deposited on a piece of silicon, as this examination depicts very small details on the surface, and the size of the particles was determined through this examination, as figure ( 3 ) shows that the size of AgNps ranges between (23.55-70.55) $\mathrm{nm}$ and a rate of ( 45.98$) \mathrm{nm}$. 


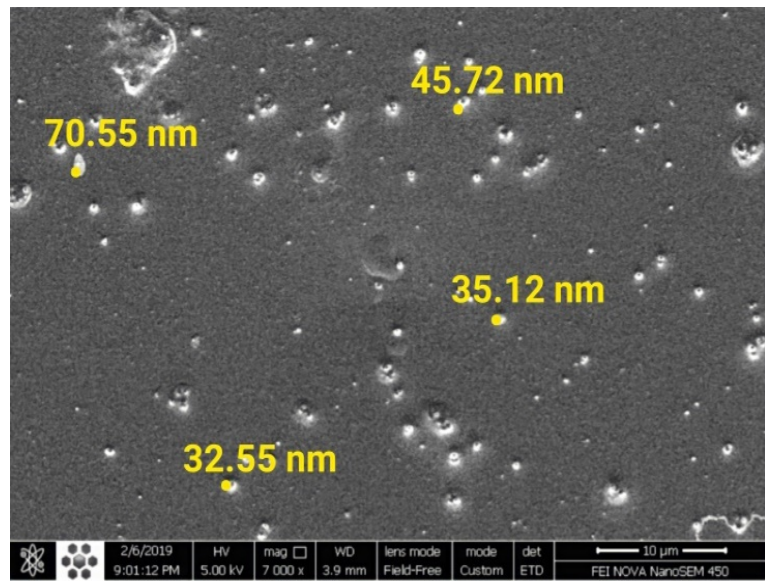

Fig 3 : Shows FESEM of silver nanoparticles

Uv-Visible spectroscopy ( UV)

The formation of nanoparticles in the plant extract was confirmed by measuring the wavelength of the plant extract .UV- visible spectroscopy refers to the absorption or analysis of spectral reflection in the spectral region of UV rays. Uv - visible showed the ability of pomegranate peel

extract to produce nanoparticles, as figure (4) shows the production of

nanoparticles at the peak of spectral emission ( 400$) \mathrm{nm}$.

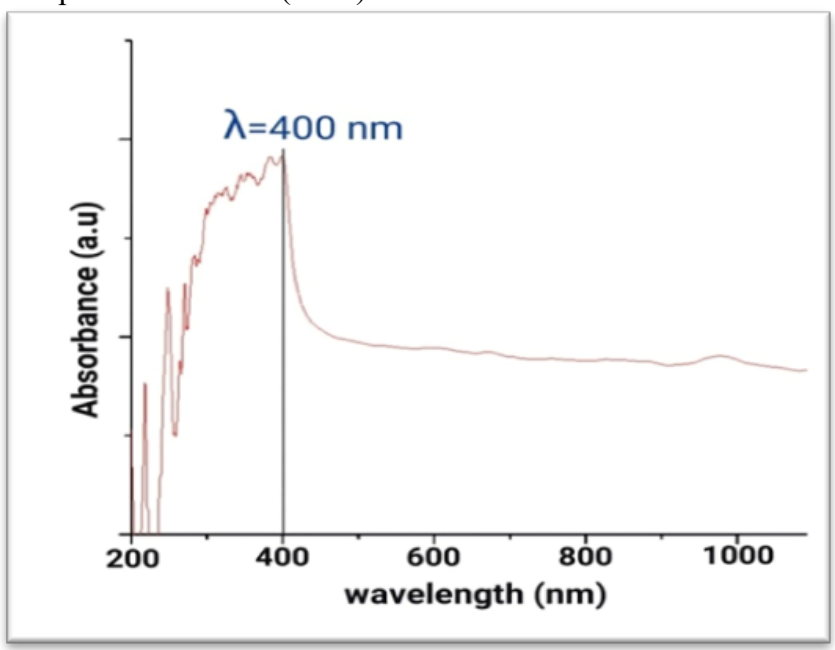

Fig (4) : Shows UV-Vis spectra of the Callicarpa maingayi extract

\section{Energy-Dispersive X-ray Spectroscopy (EDX)}

EDX measurement is used in order to know the type of chemical elements present in the sample to be examined, as each elements has it down distinctive atomic structure that gives it asset of distinct peaks in the $\mathrm{x}$-ray spectrum [10] . figure ( 5) shows that silver nanocrystals shows atypical absorption peak at energy $(0.25) \mathrm{Kev}$, and a high peak for silver and then apeak for $\mathrm{O} 2$ at energy $(0.50) \mathrm{Kev}$, and apeak for $\mathrm{AL}$ at energy ( 1.50$) \mathrm{Kev}$, table (1) shows the percentage of elements in the nanoextract of pomegrantage peels 


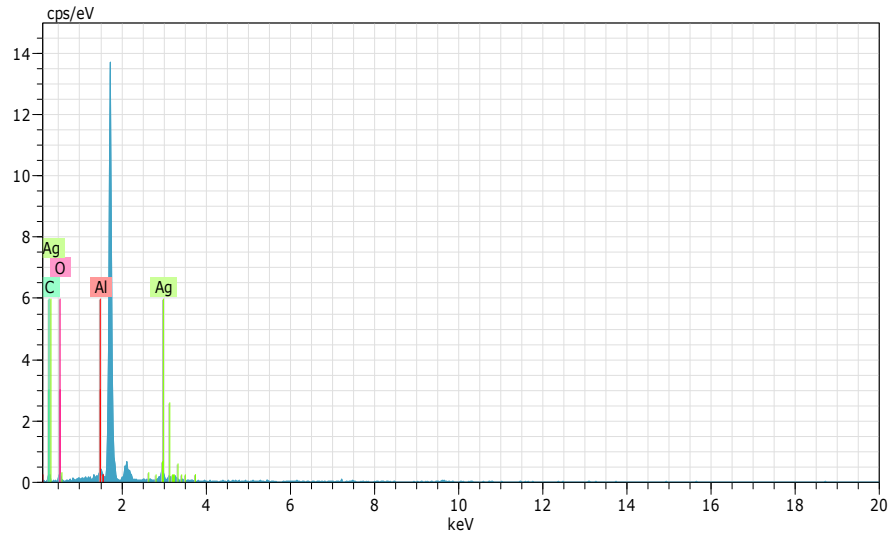

Fig (5): shows EDX analysis spectrum of silver nanoparticles

Table1: EDX results shows percentage of elements in resulting suspension

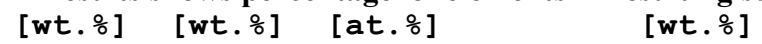

$\begin{array}{lllrrr}\text { O } 8 & \text { K-series } & 5.98 & 36.50 & 48.18 & 3.39 \\ \text { Ag } 47 & \text { L-series } & 5.37 & 32.78 & 6.42 & 0.43 \\ \text { C } 6 & \text { K-series } & 3.59 & 21.89 & 38.49 & 2.24 \\ \text { Al } 13 & \text { K-series } & 1.45 & 8.83 & 6.91 & 0.20 \\ -r & \text { Total: } & 16.38 & 100.00 & 100.00 & \end{array}$

Fourier Transform Infrared (FTIR)

We notice from figure (6) the appearance of several clear infrared peaks at ( 6346$),(3444.63) \mathrm{cm}^{-1}$ spectrum bundle ( 3467.77 ) is attributed to $(\mathrm{O}-\mathrm{H})$, spectrum bundle $(1635.52) \mathrm{cm}^{-1}$ is attributed to $(\mathrm{C}=\mathrm{O})$, and spectrum bundle $(1384.79) \mathrm{cm}^{-1}$ is attributed to $(\mathrm{CH} 3)$ as shown in figure (6) and table (2).

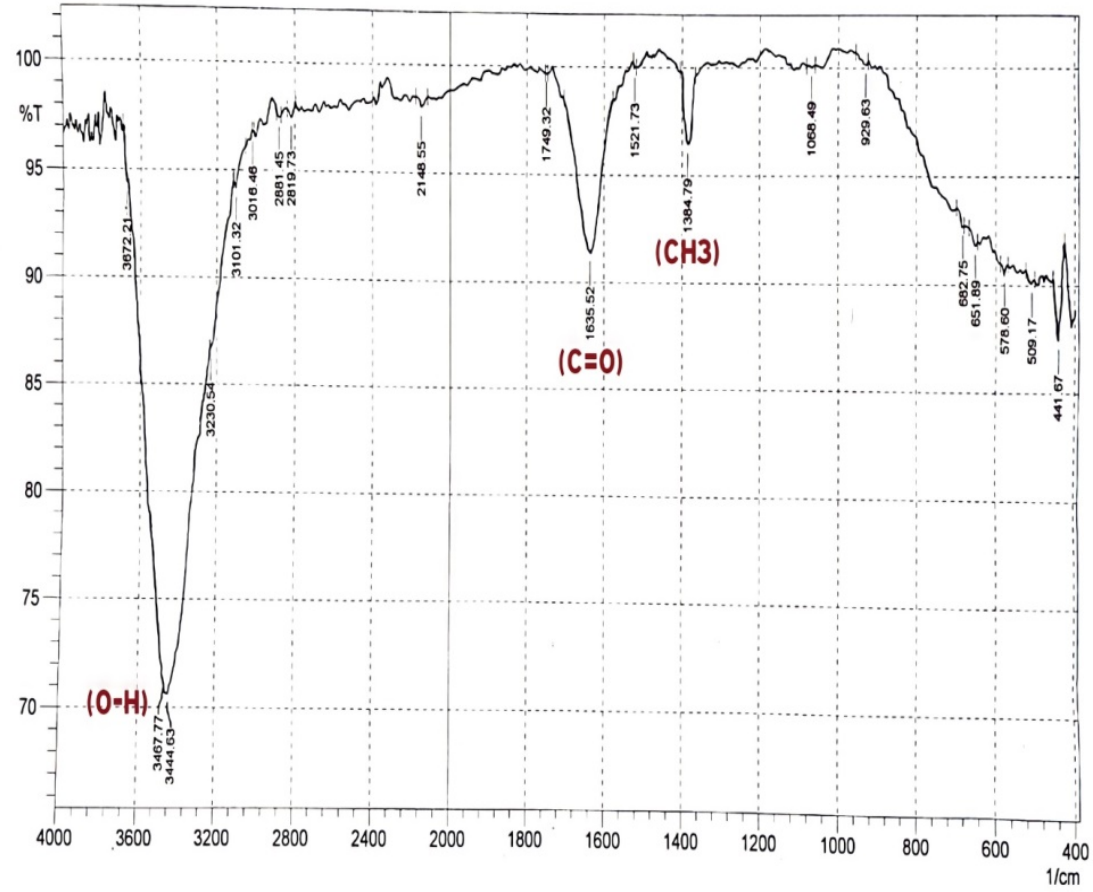

Fig (6): FTIR spectrum of extract Callicarpa maingayi 
Table2: The FTIR analysis information of Callicarpa maingayi extract

\begin{tabular}{|c|c|c|}
\hline Plant name & $\begin{array}{c}\text { Functional } \\
\text { groups }\end{array}$ & $\begin{array}{c}\text { Absorbance peak } \\
\left(\mathrm{cm}^{-1}\right)\end{array}$ \\
\hline \multirow{2}{*}{$\begin{array}{c}\text { Callicarpa } \\
\text { maingayi }\end{array}$} & O-H & $3467.77 \mathrm{~cm}^{-1}$ \\
\cline { 2 - 3 } & $\mathrm{C}=\mathrm{O}$ & $1635.52 \mathrm{~cm}^{-1}$ \\
& $\mathrm{CH3}$ & $1384.79 \mathrm{~cm}^{-1}$ \\
\cline { 2 - 3 } & & \\
\hline
\end{tabular}

\section{X-ray diffraction}

$\mathrm{X}$-ray diffraction spectrum of silver nanoparticles prepared using alcohol pomegranate peel extract . as we notice from the figure the appearance of diffraction peaks for silver due to the cubic crystal structural [11] . and the appearance of distinctive diffraction peaks in (111),(200) and (220) at the angles (38.5), (43.9) and (64.5) . and the width of these peaks is related to the size of the crystals as shown in fig (7).

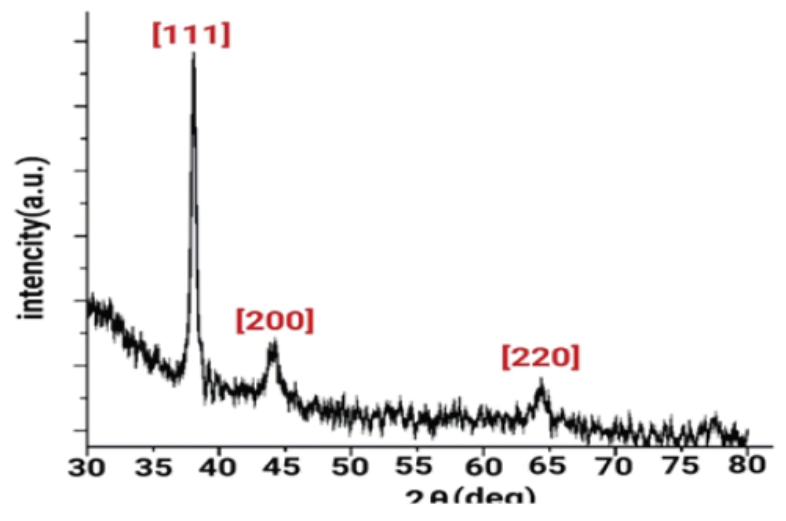

Fig (7): Shows the X-Ray diffraction of silver nanoparticles

\section{Conclusion}

Silver nanoparticles can be prepared in several ways, including chemical, physical and biological , but the biological method is one of the best methods because it does not leave toxic chemicals, and is cheap . in the biological method, nanoparticles can be prepared in three sources : bacteria, fungi and plant extracts. the biological method is the best in terms of safety and ease. In this research, the alcoholic extract of the peels of the pomegranate plant was used. the peels were collected dired and finely ground (150) gm of the plant was Taken ( 100 ) $\mathrm{ml}$ of ethanol alcohol was added to it and left for The next day. then (600) ml of silver nitrate solution was added to it then it was observed that the color of the solution changed from light yellow to dark, which indicates the formation of $\mathrm{AgNps}$. the formation of nanoparticles was confirmed by measuring the wave length of the plant extract using UV device. also the spectral infrared transmission spectra of the prepared AgNps extract were recorded using an infrared spectrophotometer ( FTIR). The nanoparticles were observed, their properties were studied their shapes were known and their size was determined through ( FESEM ). Cell shape and size were also determined using x-ray diffraction . 
Further work

Using different other plants and studying their optical properties as well as studying the optical properties of

AgNps by using transmission electron microscopy ( TEM ), Gismos measurement and Raman

measurement for the prepared nanoparticles

\section{References}

[1] - Farhan A M, Gassim R A, Kadhim N G, Mehdi W A, and Mehdi A A ( 2018 ) Synthesis of Silver Nanoparticles from Malva parviflora Extract and Effect on Ecto-5-Nucleotidase (5-NT), ADA and AMPDA Enzymes in Sera of Patients with Arthoros clerosis . Baghdad Science Journal, 14(4). 742-750 [2 ] - K.J .Sreeram, M. Nidhin and B.U .Nair . ( 2008 ). Bull.Mater.Sci . Indian Academy of sciences . 31(7):937-942.

[3] - Chou W.L .,YUD. G and Yang M.C.( 2005) . Polym- Adv.Technol .16:600-608.

[4] - Wasan Mubdir Khilkal,"Productions and studied the properties of some metals and metals oxide Nanoparticles by using Laser ablation in different solution Babylon University, Colleege of science for women Departement of Laser physics , ( 2015 ) .

[5] - Bigall, N. C.Hartling, T.Klose, M. Simon, P.Eng, L.M. Eychuller, A.Nano Latt., 8, 4588, ( 2008 ) .

[6]-Z.Tang,S.Liu,S.Dong and E.Wang .(2001).Journal of

Electroanalytical chemistry . 502:146.

[7]- Krisshnaraj.C, Jagan .EG, Rajasekar .S, Selvakumar .P, Kalaichelvan PT and Mihan N . (2010), Synthesis of Silver nanoparticles using Acalyphaindica leaf extracts and its antibacterial activity against water borne pathogens Colloids and surfaces B : Biointerfaces 76 ( 50-56)

[ 8 ] - Shameli , K., Ahmad , MB., Al- Mulla , E ,A ,J., Ibrahim , NA., Shabanzadeh,P., Rustaiyan, A ., Abdollahi ,Y., Bagheri, S., Abdol

Mohammadi ,S., Vsman , MS., and Zidan, M., ( 2012 ). Green

biosynthesis of Silver nanoparticles using Callicarpa maingayi stem

bark extraction . Molecules . 17 ( $8506-8517$ ).

[9 ] - Roy, K, Biswas .S and Banerjee .P.C, ( 2013 ), Green Synthesis Silver Nanoparticles by using Grape ( Vitis Vinifera ) Fruit Extract :characterization of particles and study of Antibacterial Activity. Research Journal of Pharmaceutical ,Biological and Chemical Science .. 4(1271-1278).

[10] - Joseph Goldstein ( 2003). Scanning Electron Microscopy and X-

Ray Microana Lysis. Springer. ISB N 978-0-306-47292-3

[11] - Yuet Ying Loo, Buong Woei Chieng, Mitsuaki Nishibuchi .(2012). Synthesis of silver Camellia Sinensis. International Journal of Nanomodicine: 7 nanoparticles by tea leaf extract from $(4263-4267)$. 